\title{
Humidity-resistant inorganic binder for sand core making in foundry practice
}

\author{
Lai Song, *Wei-hua Liu, Ying-min Li, and Fang-hai Xin \\ Shenyang University of Technology, Shenyang 110870, China
}

\begin{abstract}
The performance of sand core was improved by using the modified water glass as a binder and adding powder additives in the sand hardening process. The optimal proportion of the compound additives was determined by an orthogonal test, with a ratio of microsilica: polyvinyl alcohol solution: borax: B agent $=25: 20$ : 2: 1 . The binder accounted for $2 \%$ of the sand by weight, and the compound additives accounted for $0.96 \%$. The core box was heated to $175^{\circ} \mathrm{C}$, and the compressed hot air of $120^{\circ} \mathrm{C}$ kept blowing for $40 \mathrm{~s}$. Tensile strength was used as the main indicator to evaluate the humidity-resistance of the sand core. For the sand core, the instant tensile strength reached $0.73 \mathrm{MPa}$, the tensile strength at room temperature was $1.81 \mathrm{MPa}$, and that of sand core holding at the condition of $35^{\circ} \mathrm{C}$ and $90 \% \mathrm{RH}$ for $2 \mathrm{~h}$ and for $4 \mathrm{~h}$ reached $1.61 \mathrm{MPa}$ and $1.19 \mathrm{MPa}$, respectively. The gas evolution was $7.5 \mathrm{~mL} \cdot \mathrm{g}^{-1}$ at $850{ }^{\circ} \mathrm{C}$ for $3 \mathrm{~min}$. The residual tensile strength was $0 \mathrm{MPa}$ at $750{ }^{\circ} \mathrm{C}$ for $5 \mathrm{~min}$. Fourier-transform infrared spectroscopy analysis showed that the humidity-resistance of the core was greatly improved by the powder additives.
\end{abstract}

Key words: water glass; inorganic binder; compound additives; humidity-resistance

CLC numbers: TG222 Document code: A

Article ID: 1672-6421(2019)04-267-05

$I^{2}$ $n$ recent years, the requirement for environmental protection has become increasingly strict in foundry production $^{[1]}$. It is therefore extremely urgent to prepare new kinds of binders with no pollution to the environment. Inorganic binder has the potential to be an excellent candidate due to low gas evolution and no environmental pollution ${ }^{[2-4]}$. However, sand cores using inorganic binder are peculiarly prone to fracture due to high hygroscopicity when exposed to a high humidity environment ${ }^{[5-7]}$. So the sand cores need to be stored in a low-humidity environment. In order to improve the humidity-resistance of water glass sand, many progresses have been made in recent years. For example, Li et al. ${ }^{[8]}$ studied the composite hardening process and humidity resistance of microwavehardened water glass sand core, and silicone oil and sodium methylsilicate were introduced as modifiers to improve the humidity resistance of sand core. Wang et al. ${ }^{[9]}$ improved the humidity resistance of sand core by using alcohol-based coatings with $\mathrm{PbO}-\mathrm{ZnO}$ cryogenic ceramic powder as aggregate, where $\mathrm{Al}_{2} \mathrm{Ti}_{5}, \mathrm{NaAlO}_{2}$, $\mathrm{PbTi}_{3}$ and other substances were produced after ignition

\section{*Wei-hua Liu}

Male, born in 1968, associate professor, Ph.D. His research interest mainly focuses on foundry materials, and he has published over 30 technical papers.

E-mail: 974942647@qq.com

Received: 2018-12-12; Accepted: 2019-05-11 and sintering. The tensile strength of water glass sand core samples coated with those substances in constant humidity bottles for 4 hours was nearly 2.33 times higher than that of common sand core samples ${ }^{[9,10]}$. Wu et al. ${ }^{[11]}$ investigated the functional groups and microstructures of pure water glass, and the water glass addition with polyvinyl alcohol solution by infrared spectroscopy and scanning electron microscopy. The results showed that new functional groups appeared in the binder after adding polyvinyl alcohol solution, and a certain amount of polyvinyl alcohol showed good humidity resistance to water glass sand core.

In this work, the performance of sand core was improved by using the modified water glass as a binder and adding compound additives in sand mixing process. The powder additives consist of microsilica, polyvinyl alcohol solution, borax and B agent. During hardening, the reaction of water glass and microsilica consumed $-\mathrm{OH}$. For the first time, the hydrophobic group was formed by the irreversible gel formed between polyvinyl alcohol and borax, which reduced the content of hydrophilic groups in the binder. The innovations of this research are that the binder and powder additives are low-cost and can be easily prepared, and the preparation for the sand core does not need a secondary coating treatment. The sand core has advantages of good humidity resistance, low 
amount of binder, high strength, no toxicity, low gas evolution and good collapsibility.

\section{Materials and methods}

\subsection{Materials and equipment}

The raw sand "ZGS-50/100(60)" was acquired from Dalin, China. The modified water glass was prepared in our own laboratory, with a modulus of $2.3^{[12]}$. Polyvinyl alcohol solution was purchased from Usolf, China. B agent and borax were purchased from Liaoning Xinxing Co., Ltd., China. A coldbox/hot-box/inorganic process core shooter (MLWA1, Suzhou
Mingzhi Technology Co., Ltd. , China) was emploied in this work .

\subsection{Preparation for sand core samples}

Figure 1 shows the preparing process of the sand core samples. Firstly, the sand $(1 \mathrm{~kg})$ was mixed with binder and powder additives $(20 \mathrm{~g})$ for $60 \mathrm{~s}$. Secondly, 5\% polyvinyl alcohol solution was added in the mixture and mixed for $60 \mathrm{~s}$. Thirdly, the sand mixture was used to prepare the ' 8 ' - shape sample by core shooter. The sand was then cured by a warm-box process where the core-box was heated to $175^{\circ} \mathrm{C}$, and the compressed air was blown at $120^{\circ} \mathrm{C}$ for $40 \mathrm{~s}$ under the pressure of 5 bar. Finally, the samples were taken out to be tested.

Gas generator

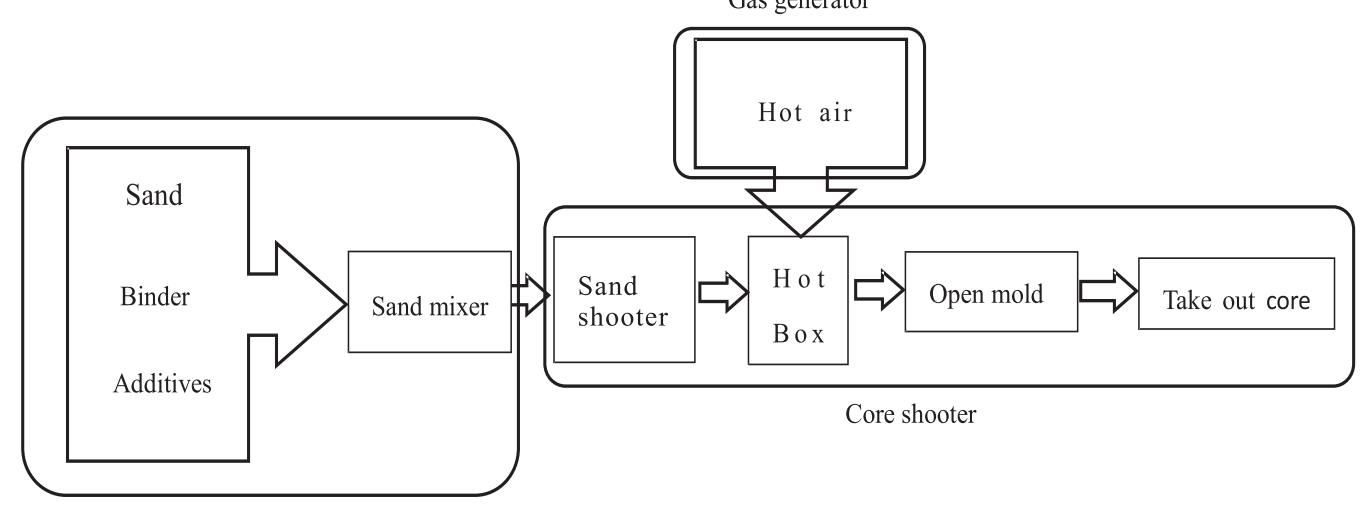

Fig. 1: Preparing process of sand core samples

\subsection{Determination for tensile strength of sand core samples}

In order to obtain the optimal proportion of the powder additives, the orthogonal levels and factors were designed and are shown in Table 1. The bond bridge of the modified binder was observed by scanning electron microscope (SEM).

Two kinds of ' 8 '-shape samples were produced with the unmodified water glass and modified water glass being their binders. The size of tensile specimen is shown in Fig. 2, The tensile strength of the prepared sand core samples was measured by ' $\mathrm{SWY}$ ' sand testing machine. A sample was put on the testing machine and gradually loaded until it was broken, and its tensile strength could be recorded. The instant tensile strength, the tensile strength at room temperature and that of samples holding at $35{ }^{\circ} \mathrm{C}$ and humidity of $90 \% \mathrm{RH}$ for $2 \mathrm{~h}$ and $4 \mathrm{~h}$ were measured. The final tensile strength was the average of five samples.

\subsection{Fourier-transform infrared spectroscopy analysis}

The Fourier-transform infrared (FT-IR) spectra of the samples

Table 1: Orthogonal factors and levels

\begin{tabular}{ccccc|} 
Levels & $\begin{array}{c}\text { Microsilica } \\
\text { A (\%) }\end{array}$ & $\begin{array}{c}\text { B agent } \\
\text { B (\%) }\end{array}$ & $\begin{array}{c}\text { Borax } \\
\text { C (\%) }\end{array}$ & $\begin{array}{c}\text { PVA aqueous } \\
\text { solution D (\%) }\end{array}$ \\
\hline 1 & 15 & 0.5 & 1 & 20 \\
2 & 25 & 1 & 1.5 & 40 \\
3 & 35 & 1.5 & 2 & 60 \\
\hline
\end{tabular}

were obtained on an IRPrestige- 21 infrared spectrometer. All the samples were placed in an oven at $40{ }^{\circ} \mathrm{C}$ for $10 \mathrm{~h}$ to ensure the complete evaporation of the water. Then, the samples were ground into very fine powder, followed by being mixed with $\mathrm{KBr}$. After that, the mixture was compressed into the pills for FT-IR analysis.

\section{Results and discussion}

The tensile strengths are shown in Table 2. It can be seen that the tensile strength of the samples decreased significantly, and the humidity resistance of the samples was poor as the storage time increased. However, the 4-hour strength reduction of the modified water glass sand core (by $0.32 \mathrm{MPa}$ ) was greater
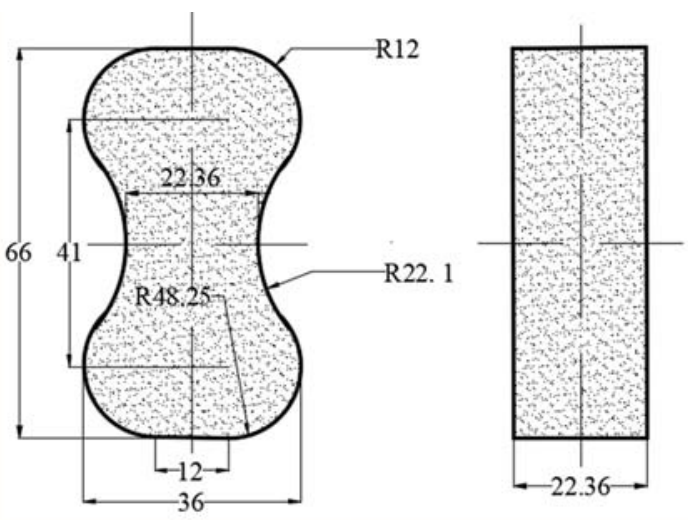

Fig. 2: Size of tensile specimen (unit: $\mathrm{mm}$ ) 
Table 2: Tensile strength of samples using different binders (MPa)

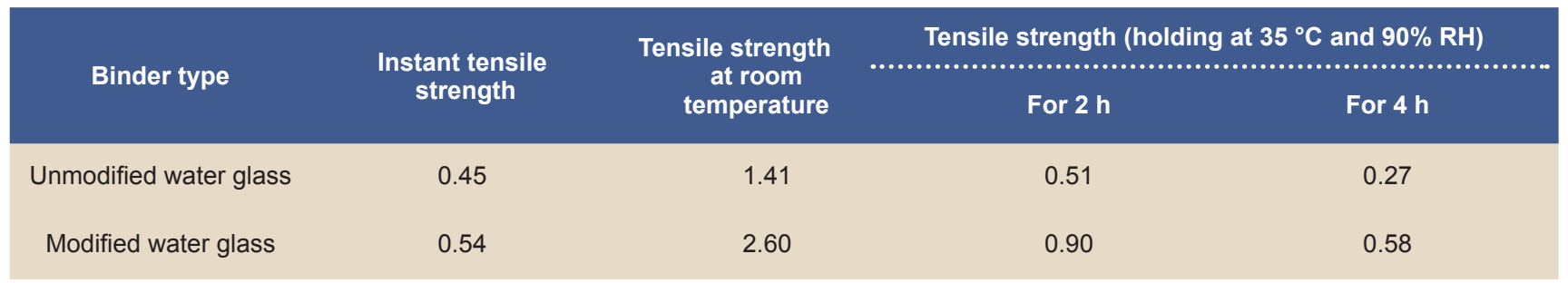

than that of the unmodified one (by $0.24 \mathrm{MPa}$ ). The results in Table 1 demonstrate the humidity resistance of the modified water glass sand is higher than that of the unmodified one. Therefore, the following tests and conclusions were based on the modified water glass.

Figure 3 shows the effects of different amounts of B agent on the tensile strength. As can be seen from the figure, the tensile strength generally decreased as the B agent increased, and the best effect was achieved when the amount of B agent accounted for $1 \%$ of the binder. That is because the B agent is a macromolecule with both hydrophilic and hydrophobic groups. The hydrophilic group in B agent can react with binder during the hardening process, and the hydrophobic group improved the humidity resistance of the sand core. In addition, there was a chemical reaction between polyvinyl alcohol solution (PVA, $5 w t . \%$ ) and borax. When the weight of the borax reached $1 \%$ of the polyvinyl alcohol solution, the irreversible gel reaction started, which improved the humidity-resistance of the sand core. The microsilica was added to improve the modulus of sodium silicate, the curing rate and the tensile strength.

To obtain the optimal proportion of the compound additives, the tensile strength at room temperature and that after $4 \mathrm{~h}$ in orthogonal experiment are shown in Table 3, Table 4 and Fig. 4. Table 3 indicates that the tensile strength of the sand core at room temperature was not positively affected by the change of the proportion of each component in the compound additives. Table 4 and Fig. 4 indicate that the optimal proportion of the compound additives was A2B2C3D1 due to the tensile strength after $4 \mathrm{~h}$ being the maximum (1.19 $\mathrm{MPa})$, and the influencing degree of each factor subjected to $\mathrm{A}>\mathrm{D}>\mathrm{B}>\mathrm{C}$. When the weight of the borax reached $1 \%$ of the polyvinyl alcohol solution, and the $\mathrm{B}$ agent was added $1 \%$ in the binder,

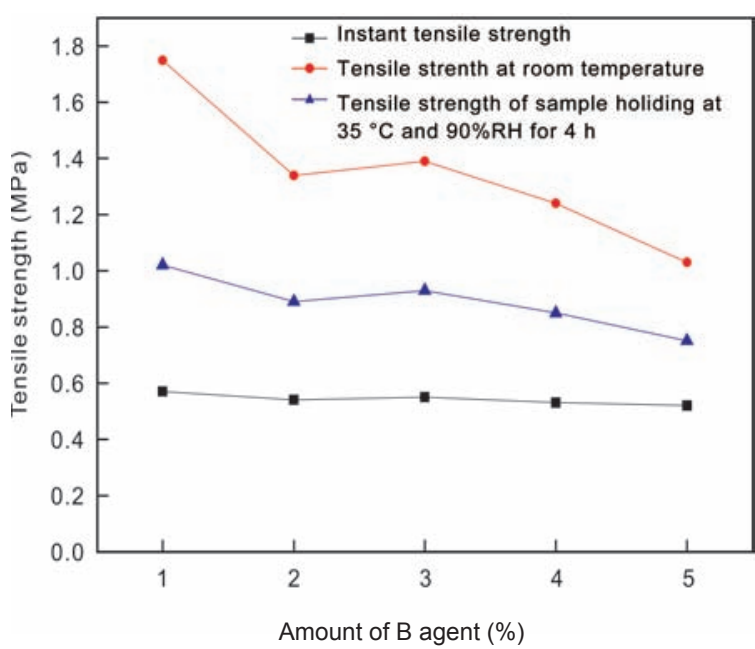

Fig. 3: Effects of different amounts of B agent on tensile strength

the sand core shows good humidity resistance.

The results of the verification test are shown in Table 5. As shown in Table 5, the optimal proportion of the compound additives was microsilica: polyvinyl alcohol solution: borax: $\mathrm{B}$ agent $=25: 20: 2: 1$. Compared with the sand core using unmodified water glass as the binder, the sand core produced by the proposed scheme showed a great improvement in the tensile strength and the humidity resistance after $2 \mathrm{~h}$ and $4 \mathrm{~h}$, as observed in Tables 2 and 5. The 2-hour tensile strength of the optimal sand core (1.61 MPa) was 3 times higher than that of the unmodified one $(0.51 \mathrm{MPa})$, and 4-hour tensile strength of the optimal sand core (1.19 MPa) was nearly 4.4 times higher than that of the unmodified one $(0.27 \mathrm{MPa})$. The increasing tensile strengths indicate the moisture absorption

Table 3: Results of orthogonal experiment

\begin{tabular}{|c|c|c|c|c|c|}
\hline $\begin{array}{l}\text { Test } \\
\text { NO. }\end{array}$ & $\begin{array}{l}\text { Microsilica } \\
\text { A (g) }\end{array}$ & $\begin{array}{l}B \text { agent } \\
B(g)\end{array}$ & $\begin{array}{c}\text { Borax } \\
\text { C (g) }\end{array}$ & $\begin{array}{l}\text { PVA aqueous } \\
\text { solution } D(g)\end{array}$ & $\begin{array}{c}\text { Tensile strength at room } \\
\text { temperature (MPa) }\end{array}$ \\
\hline 1 & A1 & B1 & C1 & D1 & 1.56 \\
\hline 2 & A1 & B2 & C2 & D2 & 1.31 \\
\hline 3 & A1 & B3 & C3 & D3 & 1.31 \\
\hline 4 & A2 & B1 & $\mathrm{C} 2$ & D3 & 1.44 \\
\hline 5 & A2 & B2 & C3 & D1 & 1.81 \\
\hline 6 & A2 & B3 & C1 & D2 & 1.58 \\
\hline 7 & A3 & B1 & C3 & D2 & 1.59 \\
\hline 8 & A3 & B2 & C1 & D3 & 1.57 \\
\hline 9 & A3 & B3 & $\mathrm{C} 2$ & D1 & 1.40 \\
\hline
\end{tabular}


resistance of the water glass core was obviously improved.

The bond bridge and the fracture on it are shown in Figs. 5(a) and (b). As can be seen from Fig. 5(b), the joint failure by

Table 4: Results and analysis of orthogonal experiment about tensile strength after $4 \mathrm{~h}$

\begin{tabular}{cccccc}
$\begin{array}{c}\text { Test } \\
\text { NO. }\end{array}$ & $\begin{array}{c}\text { Microsilica } \\
\text { A (g) }\end{array}$ & $\begin{array}{c}\text { B agent } \\
\text { B (g) }\end{array}$ & $\begin{array}{c}\text { Borax } \\
\text { C (g) }\end{array}$ & $\begin{array}{c}\text { PVA aqueous } \\
\text { solution D (g) }\end{array}$ & $\begin{array}{c}\text { Tensile } \\
\text { strength } \\
\text { after } \\
\mathbf{4} \text { (MPa) }\end{array}$ \\
\hline 1 & A1 & B1 & C1 & D1 & 0.69 \\
2 & A1 & B2 & C2 & D2 & 0.68 \\
3 & A1 & B3 & C3 & D3 & 0.61 \\
4 & A2 & B1 & C2 & D3 & 0.57 \\
5 & A2 & B2 & C3 & D1 & 1.19 \\
6 & A2 & B3 & C1 & D2 & 1.12 \\
7 & A3 & B1 & C3 & D2 & 0.93 \\
8 & A3 & B2 & C1 & D3 & 0.91 \\
9 & A3 & B3 & C2 & D1 & 1.00 \\
$k_{1}$ & 0.660 & 0.730 & 0.907 & 0.960 & \\
$k_{2}$ & 0.963 & 0.927 & 0.750 & 0.910 & \\
$k_{3}$ & 0.947 & 0.910 & 0.910 & 0.697 & \\
$R_{\mathrm{i}}$ & 0.300 & 0.197 & 0.160 & 0.263 & \\
\hline & & & & &
\end{tabular}
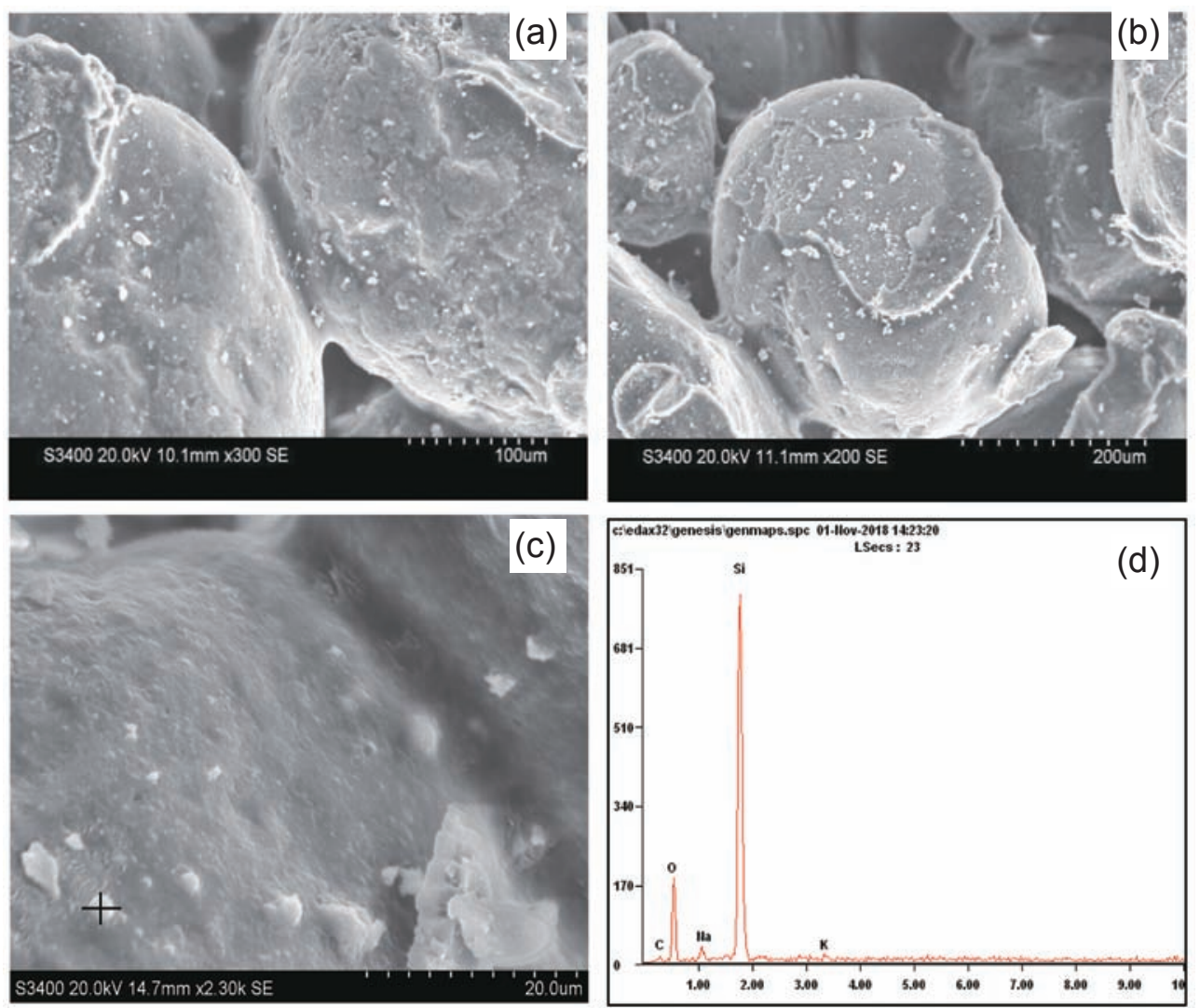

Fig. 5: Surface morphology of bond bridge and fracture: (a) bond bridge; (b) fracture of bond bridge; (c) additives on surface of hardened sand; (d) elemental analysis of additives shear tension was featured by the mixture failure of interface and cohesive force, demonstrating the good adhesive strength of the modified binder. It can be seen from Fig. 5(c) that the

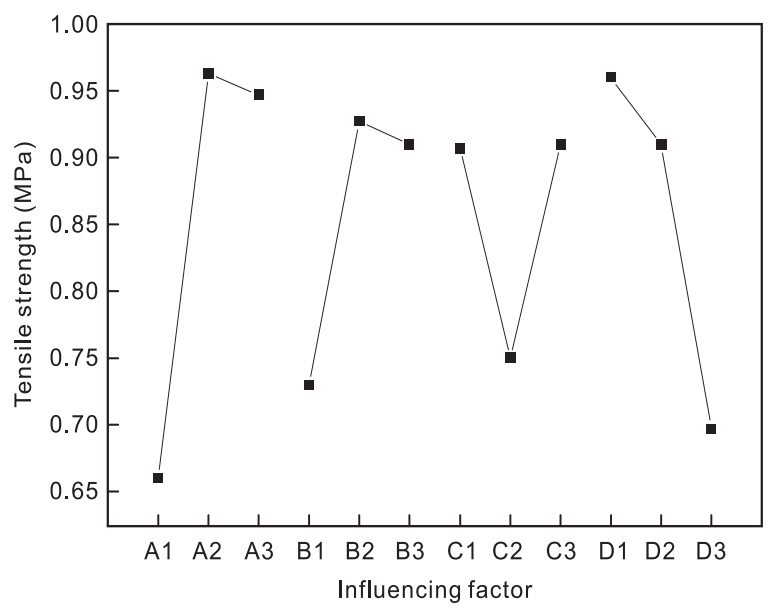

Fig. 4: Range analysis of orthogonal experiment

Table 5: Tensile strength of sand core with optimal proportion (MPa)

$\begin{array}{cccc}\begin{array}{c}\text { Optimal } \\ \text { proportion }\end{array} & \begin{array}{c}\text { Instant } \\ \text { tensile } \\ \text { strength }\end{array} & \begin{array}{c}\text { Tensile } \\ \text { strength } \\ \text { at room } \\ \text { temperature }\end{array} & \begin{array}{c}\text { Tensile strength } \\ \text { (holding at } 35{ }^{\circ} \mathrm{C} \text { and } \\ 90 \% \mathrm{RH})\end{array} \\ \text { For } 2 \mathrm{~h} \quad \text { For } \mathbf{~ h}\end{array}$


white particles were uniformly dispersed in the binder and played a reinforcing role. Elemental analysis of the white dots shows they are powdery additives covered with binders, as shown in Fig. 5(d).

The bonded materials easily absorb the water vapor in the surrounding environment during storage, mainly due to the chemical bonds of $-\mathrm{OH}$ and $-\mathrm{ONa}$. The samples were characterized and analyzed by infrared spectrogram (IR) and the results are shown in Fig. 6. As can be observed in Fig. 6, a sharp absorption peak occurred near $3,424 \mathrm{~cm}^{-1}$, indicating the great reduction of hydroxyl group of -OH. By contrast, the hydrophobic groups of carbonyl peak $\left(2,362 \mathrm{~cm}^{-1}\right)$, the B-O characteristic peak $\left(2,250-2,500 \mathrm{~cm}^{-1}\right)$ and the Si-C characteristic peak $\left(763 \mathrm{~cm}^{-1}\right)$ occurred ${ }^{[5]}$. These phenomena indicate that borax and polyvinyl alcohol participated in the crosslink reaction in the excessive hardening of the binder.

Other process properties of the binder are shown in Table 6, which shows the dynamic viscosity of the binder is not high (78 MPa.s ), the mobility of molding (core) sand is $2.15 \mathrm{~g}$, and the effective time of molding sand is enough $(>3 \mathrm{~h})$, which can ensure the good quality of sand mold and core. The high temperature residual strength is low, which effectively improves the sand shakeout cleaning. The gas generation is

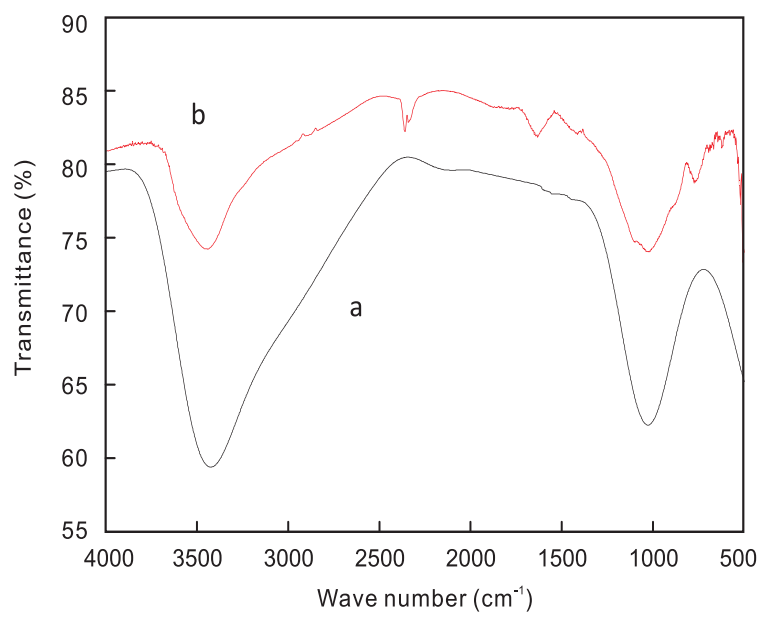

Fig. 6: Infrared spectrogram of samples FT-IR line of unmodified binder (a) and modified binder with additives (b)

Table 6: Process properties of binder

\begin{tabular}{|c|c|}
\hline Process properties & Results \\
\hline Dynamic viscosity of the binder (MPa·s) & 78 \\
\hline Mobility of molding (core) sand (g) & 2.15 \\
\hline The effective time of molding sand $(\mathrm{h})$ & $>3$ \\
\hline $\begin{array}{l}\text { High temperature residual strength }\left(750^{\circ} \mathrm{C} \times 5 \mathrm{~min}\right) \\
\text { (MPa) }\end{array}$ & 0 \\
\hline Gas evolution $\left(850^{\circ} \mathrm{C} \times 3 \mathrm{~min}\right)\left(\mathrm{mL} \cdot \mathrm{g}^{-1}\right)$ & 7.5 \\
\hline
\end{tabular}

low, which can reduce the gas cavity occurring in casting. To sum up, the comprehensive properties of the modified binder are good enough to be used in casting production.

\section{Conclusion}

The water glass, as a binder of sand core, was modified in this work. The optimal proportion of the powder additives was microsilica: polyvinyl alcohol solution: borax: B agent =25: 20: $2: 1$, and their weight accounted for $0.96 \%$ of the entire sand. The tensile strengths demonstrate the humidity resistance of the modified water glass sand is higher than that of the unmodified one. When the temperature of the core box was $175^{\circ} \mathrm{C}$, and the hot air was blown at $120^{\circ} \mathrm{C}$ for $40 \mathrm{~s}$, the instant tensile strength of the sand core reached $0.73 \mathrm{MPa}$, the tensile strengthat room temperature was $1.81 \mathrm{MPa}$, the tensile strength of the sand core samples holding at $35{ }^{\circ} \mathrm{C}$ and $90 \%$ $\mathrm{RH}$ for $2 \mathrm{~h}$ reached $1.61 \mathrm{MPa}$, and that for $4 \mathrm{~h}$ was $1.19 \mathrm{MPa}$. It is wroth noting that the 4 -h tensile strength $(1.19 \mathrm{MPa})$ of the modified sand core was more than 4 times higher than that of the unmodifed one ( $0.27 \mathrm{MPa})$. The powder additives can participate in the crosslink of binder during curing, and improve the humidity-resistance of the sand core. The gas evolution of sand core was $7.5 \mathrm{~mL} \cdot \mathrm{g}^{-1}$ at $850{ }^{\circ} \mathrm{C}$ for $3 \mathrm{~min}$, and the residual strength of the sand core was $0 \mathrm{MPa}$ under the condition of $750{ }^{\circ} \mathrm{C}$ for $5 \mathrm{~min}$.

\section{References}

[1] Liu Weihua, Wang Tianshu, Li Yingmin, et al. Preparation of a new animal glue binder for foundry use. China foundry, 2016, 13(4): 238242.

[2] Necip Ünlü, Ahmet Odabaş. Development and Evaluation of a New Eco-friendly Sodium Silicate-Based Binder System. International Journal of Metalcasting, 2018.

[3] Zhou Jingyi. Application of Sodium Silicate Inorganic Binder on Foundry Production at Home and Abroad and Its Latest Development. Foundry, 2012, 61(3):237-245. (In Chinese)

[4] Zaretskiy L. Hydrous Solid Silicates in New Foundry Binders. International Journal of Metalcasting, 2018, 12(2): 275-291.

[5] Wang Jina, Xu Kaidong, Fan Zitian. Study on Moisture Absorption Mechanism of Sodium Silicate Sands Hardened by Typical Hardening Technology. Hot Working Technology, 2012, 41(13): 45-48. (In Chinese)

[6] Zaretskiy L. Modified Silicate Binders New Developments and Applications. International Journal of Metalcasting, 2015, 10(1): 1-12.

[7] Zhou Jingyi. Aplication of water glass inorganic binder to foundry production at home and abroad and its latest development. Foundry, 2012, 61(3): 237-245. (In Chinese)

[8] Li Xuejie. Investigating on the Composite Hardening Processes and humidity-resistance of the Sodium Silicate Sand Hardened by Microwave Heating Process. Huazhong University of Science and Technology, 2013 (In Chinese).

[9] Wang Huafang. Foundations of Key Technology of the Sodium Silicate Sand Casting Process Curing with Microwave. Huazhong University of Science and Technology, 2012. (In Chinese)

[10] Liu Fuchu, Fan Zitian, Liu Xinwang, et al. Research on humidityresistance of Sodium Silicate Sand Hardened by Twice Microwave Heating Process. Advanced Manufacturing Processes, 2014, 29(2): 4

[11] Wu Xiangqing, Fan Zitian, Yu Tao. Effect of Polyvinyl Alcohol on humidity-resistance of Sodium Silicate-Bonded Sand Hardened by Microwave Reheating. Foundry, 2010, 59(6): 549-552. (In Chinese)

[12] Liu Weihua, Song Lai, Li Ying-min. Research on a Modified Inorganic Binder Hardened by Compound Technics. Foundry, 2016(11): 10561059. (In Chinese)

[13] Xu Jin. Infrared spectroscopy analysis of modifined sodium silicate. Foundry, 2008, 57(8): 834-837. (In Chinese) 